\title{
Protein Regulation in Signal Transduction
}

\section{Michael J. Lee and Michael B. Yaffe}

David H. Koch Institute for Integrative Cancer Research at MIT, Department of Biology and Department of Biological Engineering, Massachusetts Institute of Technology, Cambridge, Massachusetts 02139

Correspondence: myaffe@mit.edu

\section{SUMMARY}

Cells must respond to a diverse, complex, and ever-changing mix of signals, using a fairly limited set of parts. Changes in protein level, protein localization, protein activity, and protein-protein interactions are critical aspects of signal transduction, allowing cells to respond highly specifically to a nearly limitless set of cues and also to vary the sensitivity, duration, and dynamics of the response. Signal-dependent changes in levels of gene expression and protein synthesis play an important role in regulation of protein levels, whereas posttranslational modifications of proteins regulate their degradation, localization, and functional interactions. Protein ubiquitylation, for example, can direct proteins to the proteasome for degradation or provide a signal that regulates their interactions and/or location within the cell. Similarly, protein phosphorylation by specific kinases is a key mechanism for augmenting protein activity and relaying signals to other proteins that possess domains that recognize the phosphorylated residues.

\section{Outline}

1 Introduction

2 Posttranslational modifications and the regulation of protein activity

3 Regulation of protein-protein interaction

4 Regulation of protein location
5 Regulation of protein production

6 Protein degradation

7 Concluding remarks: What does the future hold?

References

Editors: Lewis Cantley, Tony Hunter, Richard Sever, and Jeremy Thorner

Additional Perspectives on Signal Transduction available at www.cshperspectives.org 


\section{INTRODUCTION}

Signal transduction processes are, in many respects, protein-driven events. One common way to describe these circuits involves designating different proteins, or modular domains within an individual protein, as "readers," "writers," and "erasers." In this model, catalytic domains that add specific posttranslational modifications, such as kinases and acetyltransferases, are called writers because they leave behind a physical mark on the proteins they act on. Conversely, phosphatases, deacetylases, and other enzymes that remove these modifications are examples of erasers. In addition to writers and erasers, there are also domains that bind to specific posttranslationally modified or unmodified sequences of amino acids. These types of domains read the sequences produced by writers and erasers and are therefore called readers. These readers can be involved in protein-protein interactions or interactions between two parts of the same protein. Other readers can bind directly to specific phospho- and neutral lipids, or to specific ions, such as calcium, rather than to amino acid sequences. The targets of these readers, writers, and erasers are often short amino acid sequences (typically three to 15 amino acids in length) called motifs. Using these modular parts, cells dynamically encode information in response to environmental, chemical, or developmental stimuli, to transduce the signal (see Table 1).

For some cellular processes, the mere presence of a protein, monitored, for example, by the levels of its RNA transcript, is sufficient to provide insight into the current state of the cell. In contrast, this provides relatively limited information about the current state of a signaling network, primarily because an amazing amount of regulation occurs at the protein level, via control of the readers, writers, and erasers. Moreover, this occurs dynamically, reversibly, and sometimes very quickly. Below, we focus on the basic mechanisms of regulation that occur at the level of the protein, specifically focusing on how signal transduction can control protein number, protein localization, protein activity, and protein-protein interactions.

\section{POSTTRANSLATIONAL MODIFICATIONS AND THE REGULATION OF PROTEIN ACTIVITY}

Many signaling proteins have intrinsic enzymatic activities. For example, they may contain catalytic domains capable of phosphorylating or dephosphorylating proteins, lipids, or sugars (kinases) or hydrolyzing specific lipids or phospholipids (lipases and phospholipases, respectively). In addition to performing such covalent posttranslational

Table 1. Examples of modular domain readers of motifs and protein/lipid posttranslational modifications

\begin{tabular}{|c|c|c|c|}
\hline $\begin{array}{l}\text { Modular protein } \\
\text { domain reader }\end{array}$ & Posttranslation modification recognized (if any) & Example motifs & Biological processes \\
\hline SH2 domain & Phosphotyrosine & $\operatorname{pYxx} \varphi$ & Growth factor signaling \\
\hline $\mathrm{SH} 3$ domain & None, usually recognizes proline-rich motifs & RxxPxxP, PxxPxR/K & Signaling scaffolds \\
\hline $14-3-3$ & Phosphoserine/phosphothreonine & $\begin{array}{l}\mathrm{RSx}(\mathrm{pS} / \mathrm{pT}) \mathrm{xP} \\
\quad \mathrm{Rxx}(\mathrm{pS} / \mathrm{pT}) \mathrm{xP}\end{array}$ & Chaperone/scaffold, subcellular localization \\
\hline FHA domain & Phosphothreonine & $\mathrm{p} T \mathrm{xx} \varphi, \mathrm{p} \operatorname{TxxD}$ & $\begin{array}{l}\text { DNA damage response, gene expression, } \\
\text { transport }\end{array}$ \\
\hline BRCT domain & Phosphoserine/phosphothreonine & $(\mathrm{pS} / \mathrm{pT}) \mathrm{xx} \varphi$ & DNA damage response \\
\hline Polo-box domain & Phosphoserine/phosphothreonine & $\mathrm{S}(\mathrm{pS} / \mathrm{pT}) \mathrm{P} / \mathrm{X}$ & Mitotic control by Polo-like kinases \\
\hline WW domain & $\begin{array}{l}\text { Most do not recognize any PTMS; a few } \\
\text { recognize phosphoserine/phosphothreonine }\end{array}$ & $\begin{array}{l}\text { PPxY, PPLP, PPR } \\
\quad(\mathrm{pS} / \mathrm{pT}) \mathrm{P}\end{array}$ & $\begin{array}{l}\text { Gene transcription, proline isomerization } \\
\text { and cell-cycle control, development }\end{array}$ \\
\hline Bromo domain & Acetyl-lysine & - & $\begin{array}{l}\text { Gene expression, chromatin structure, and } \\
\text { remodeling }\end{array}$ \\
\hline Chromo domain & Methyl-lysine & - & Chromatin structure and remodeling \\
\hline Tudor domain & Methyl-lysine & - & $\begin{array}{l}\text { Chromatin structure and remodeling, DNA } \\
\text { damage response }\end{array}$ \\
\hline EVH1 domain & None, usually recognizes Pro-rich motifs & $\mathrm{FPX} \varphi \mathrm{P}, \mathrm{PPxxF}$ & $\begin{array}{l}\text { Actin cytoskeleton control, } \\
\text { neurotransmission }\end{array}$ \\
\hline PX domain & $\begin{array}{l}\text { Phosphatidyl-3-phosphate, -3,4-bisphosphate, } \\
\text { and -3,4,5-trisphosphate }\end{array}$ & (Not applicable) & $\begin{array}{l}\text { Membrane targeting and trafficking, } \\
\text { endosomal sorting }\end{array}$ \\
\hline PH domain & $\begin{array}{l}\text { Phosphatidyl-4,5-bisphosphate, }-3,4 \text { - } \\
\text { bisphosphate, and -3,4,5-trisphosphate }\end{array}$ & (Not applicable) & Membrane trafficking, cytoskeletal control \\
\hline FYVE domain & Phosphatidyl-3-phosphate & (Not applicable) & Vacuolar protein sorting, endosomal sorting \\
\hline
\end{tabular}

Additional motifs beyond those shown are also recognized. (-) No distinct motif has emerged. (Not applicable) Lipid posttranslational modifications rather than protein sequence motifs.

pY, Phosphotyrosine; pS, phosphoserine; pT, phosphothreonine; F, hydrophobic amino acids. 
modifications, signaling proteins may also stimulate the exchange or hydrolysis of nucleotides in nucleotide-binding proteins such as small $\mathrm{G}$ proteins and heterotrimeric $\mathrm{G}$ proteins by acting as guanine-nucleotide exchange factors (GEFs) or GTPase-activating proteins (GAPs), respectively. Other types of catalytic domains participate in the formation of cyclic nucleotides such as cyclic AMP (cAMP) or cyclic GMP (cGMP) (Newton et al. 2014), or synthesize specific types of gas molecules that are involved in signaling, such as nitric oxide, superoxide, and other reactive oxygen and nitrogen species.

The activity of these signaling molecules must be tightly controlled so that the products of the reactions that they catalyze-phospholipids, phosphoproteins, gases, activated or inactivated $G$ proteins - are only produced at the appropriate time and place. Some of this control occurs through regulation of protein levels or protein localization, but much of it involves regulation of protein activity by posttranslational modification of the signaling molecule itself, intramolecular interactions between different domains within the protein, and/or intermolecular interactions with other proteins. In each case, this may involve a phenomenon known as allostery, in which the site where the control is exerted (e.g., where the domains interact) is different from the site where catalysis occurs. Transmission of information via a conformational change allows the allosteric site to control the protein's catalytic activity, even though the two may be far removed in physical space (Fig. 1). Key examples in signaling include binding of calcium to calmodulin to activate calcium/calmodulin-dependent protein kinases (CaM kinases), and binding of cyclic nucleotides to activate protein kinase A (PKA) and protein kinase G (PKG) (see Newton et al. 2014).

\subsection{Posttranslational Modifications}

Proteins can be exquisitely regulated by relatively small covalent changes to their basic chemical structure. These posttranslational modifications can profoundly alter a protein's activity, localization, stability, and/or binding partners, and therefore constitute the "front line" of many signaling systems within the cell. More than 350 different posttranslational modifications have been discovered, many of which are reversible.

One of the first types of protein posttranslational modifications to be identified was phosphorylation. Although
A

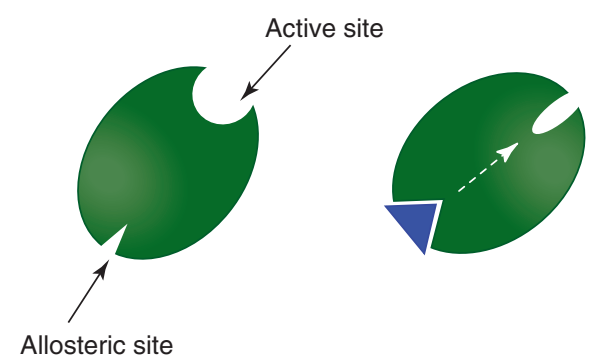

B

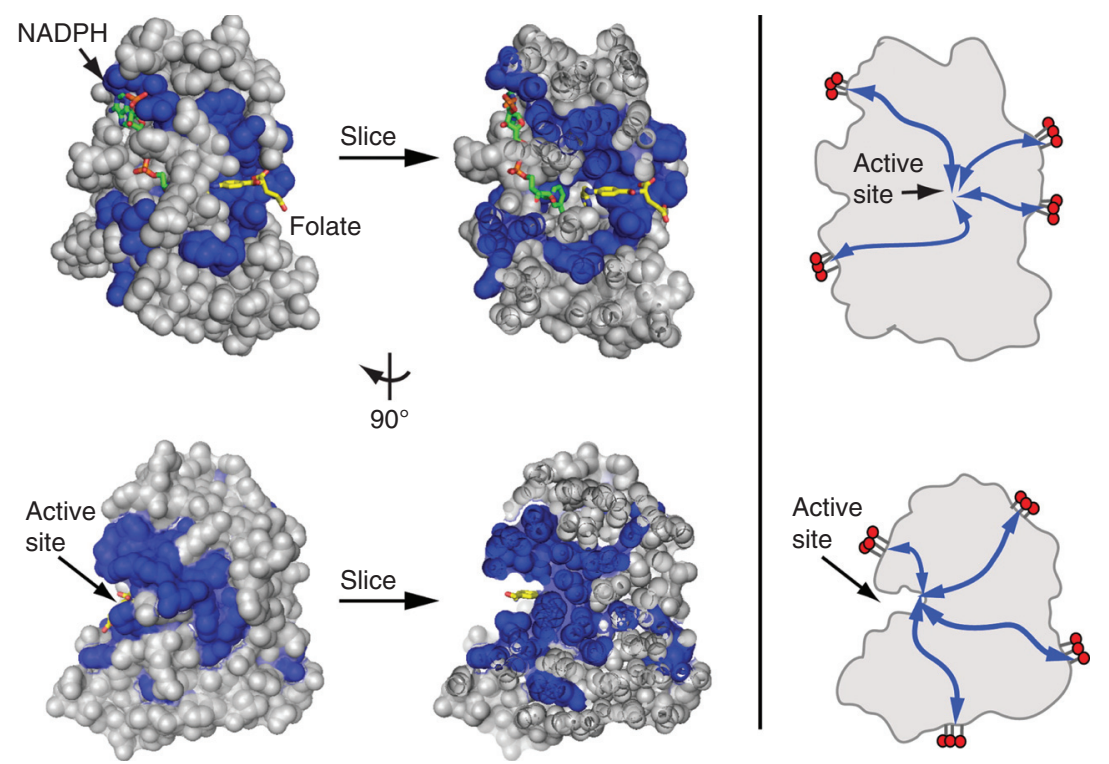

Figure 1. Allosteric modulation of protein activity. $(A)$ Cartoon example of protein allostery. In this example, an allosteric-regulation site exists in a region of the protein that is spatially distinct from the active site. Modulation of the allosteric site (through posttranslational modification or the binding of a ligand, cofactor, or protein) causes changes in the active site. Importantly, these changes can be either activating or inhibiting. (B) Allosteric regulation of dihydrofolate reductase (DHFR). (Left panels) Two surface views of the DHFR enzyme, highlighting the active site (bound to folate), cofactor binding site (bound to NADPH), and residues involved in allosteric communication between the two sites (shown in blue). (Middle panels) A view of a slice through the protein core. (Right panels) A cartoon representation of the slice mappings shown in $B$. (Figure generously supplied by Rama Ranganathan and Cell Press.) 
phosphorus was first noted as a trace element in purified egg white by Gerrit Mulder in 1835 (Mulder would subsequently invent the term protein to describe such materials), it was not until 1906 that an isolated cleavage fragment from a single protein, vitellin, was shown to contain a constant composition of $\sim 10 \%$ phosphorus (Levene and Alsberg 1906). Subsequent studies in the 1930s revealed that the hydrolysis products of vitellin included serinephosphoric acid, indicating that the phosphorus was part of a covalent modification of the protein's constituent amino acids (Lipmann and Levene 1932). In the 1950s, George Burnett and Eugene Kennedy identified an enzymatic activity in mitochondrial lysates that was capable of transferring radioactive phosphate to exogenous substrates (Burnett and Kennedy 1954), but it was not until the pioneering work of Edwin Krebs and Edmond Fischer that protein phosphorylation was shown to reversibly regulate a key biological process (Krebs and Fischer 1956) - in this case, controlling whether glucose molecules are stored as polymers of glycogen or glycogen molecules are broken down to supply the body with glucose.

Using kinases as writers, phosphate groups are added by formation of esters with amino acids whose side chains contain alcohols. In mammals, the vast majority of protein phosphorylation occurs on serine residues $(\sim 85 \%)$, with a lesser amount on threonine $(\sim 15 \%)$ and only a tiny fraction on tyrosine residues $(\sim 0.4 \%)$. In addition to being relatively rare, tyrosine phosphorylation is restricted to higher eukaryotes, having evolved just before the origin of the metazoan lineage. Nevertheless, tyrosine phosphorylation seems to be particularly important in signaling and is frequently dysregulated in cancer. A handful of other residues can also be phosphorylated, including histidine, aspartic acid, arginine, and lysine. These modifications are typically labile and difficult to purify/study, but it is becoming increasingly clear that histidine phosphorylation, for example, is relatively common and an important player in many signaling systems.

Protein phosphorylation controls the functions of proteins through a variety of different molecular mechanisms. At physiological $\mathrm{pH}$, the addition of a phosphate group adds about 1.5 electrostatic units of negative charge. In some cases, this negative charge can drive the formation of ionic bonds with positively charged residues, such as lysine and arginine, in other parts of the protein. In enzymes, these new bonds can shift the positions of $\alpha$ helices and loops in the protein to make the enzyme more or less active. For example, many protein kinases themselves are phosphorylated on residues in a region called the activation loop. Ionic interactions and hydrogen bonds involving these phosphorylated residues to nearby arginine and lysine residues lead to a dramatic rearrangement of the protein that opens up the binding site for ATP and substrates, while simultaneously reorienting the catalytic residues into a conformation that allows the protein kinase to transfer a phosphate group from ATP to a serine, threonine, or tyrosine residue on the substrate (Fig. 2). Because protein kinases often both catalyze the phosphorylation of proteins and are themselves substrates for other, upstream protein kinases, they can be linked together into pathways where one protein kinase phosphorylates another, which then phosphorylates a third, which then phosphorylates some other type of protein. This creates a signal amplifier in which the activity of the first kinase is magnified by the catalytic activities of the other kinases downstream from it in the pathway and is a particularly prominent type of signaling circuit used by mitogen-activated protein kinases (MAPKs) (see Morrison 2012). Phosphorylation is negatively regulated by a class of erasers called phosphatases, which are grouped into three main families based on sequence and structural similarity: phosphoprotein phosphatases, protein phosphatase metal-ion-dependent phosphatases, and protein tyrosine phosphatases. Each family is also further divided into subfamilies based on mechanisms of catalysis and substrate specificity.

Besides changing the enzymatic activity of a protein, phosphorylation can also disrupt the interactions between two or more proteins or cause two proteins to interact (see below), often changing the subcellular location of the phosphorylated protein.

A second common reversible posttranslational modification of proteins is acetylation. In this case, the positively charged $\varepsilon$ amino groups on lysine residues are converted into neutral amides by the addition of acetate. This loss of positive charge prevents the acetylated lysines from making electrostatic interactions with phosphate groups and is therefore a prominent posttranslational modification found on DNA-binding histones. Because the DNA backbone is built from esters of phosphates and sugars, acetylation weakens binding of the histones in nucleosomes to DNA, allowing other DNA-binding proteins, such as transcription factors and RNA polymerase, to bind instead. This often results in changes in chromatin structure and transcriptional activity. Acetylation is also common in enzymes involved in metabolism (Wang et al. 2010) and probably functions, at least in part, by changing the activity of the enzyme, in a similar way to protein phosphorylation. Like phosphorylation, protein acetylation can also drive two proteins to bind to each other if one of the proteins has a domain that specifically recognizes acetyl-lysine (e.g., a bromo domain), or it can specifically enhance the dynamics of recruitment of other proteins to the acetylated protein relative to the unmodified form. For example, acetylation of the DNA damage kinase ATM by the acetyl- 


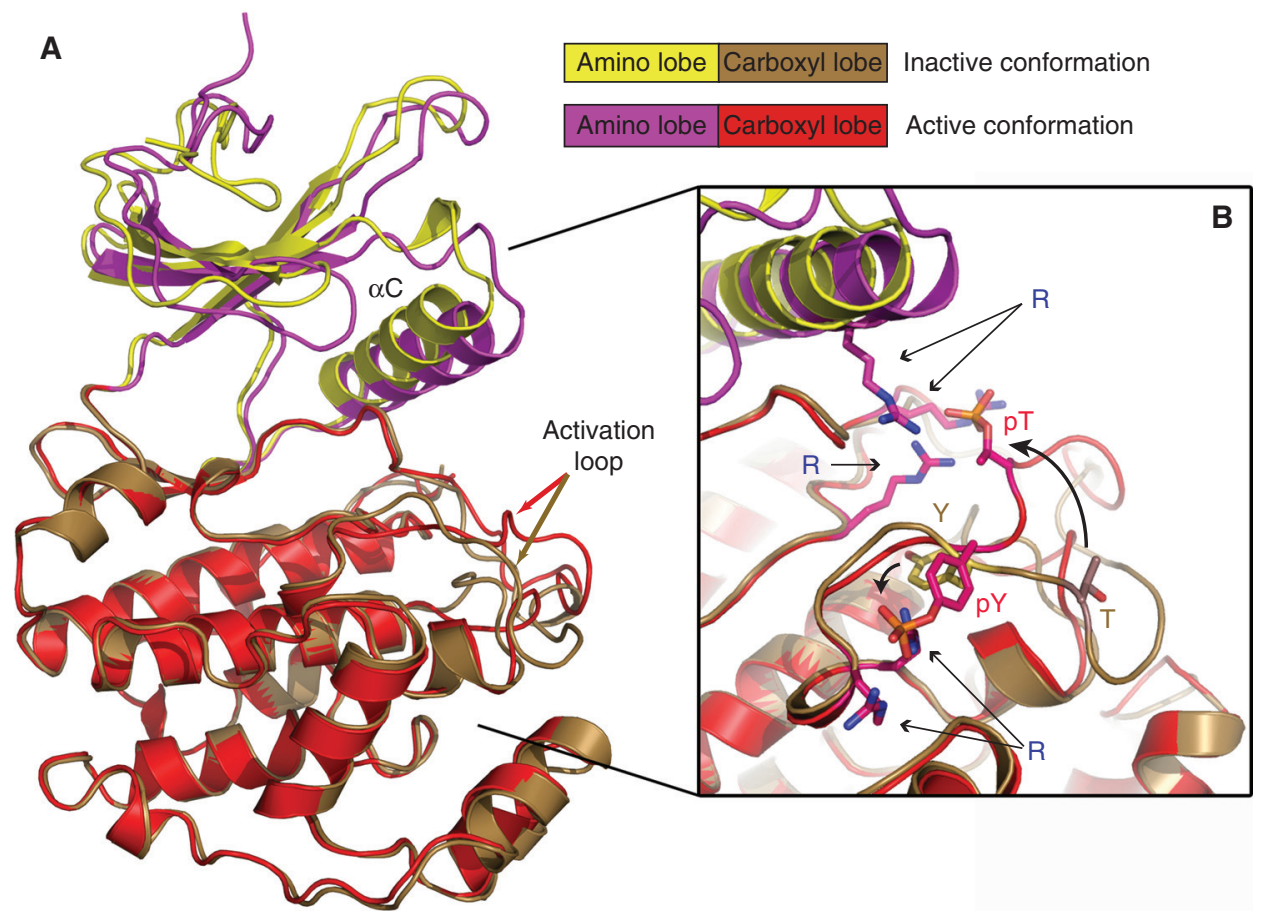

Figure 2. Mechanism of kinase activation. (A) Conformational changes in protein kinases upon phosphorylation enhance their catalytic ability. The structure of ERK2, an MAPK, is shown in its inactive nonphosphorylated state and its active phosphorylated state. The carboxy-terminal lobes of the kinase in both states (brown and red, respectively) have been superimposed. Note that following phosphorylation of the activation loop, there is a marked rotation and reorientation of the amino-terminal lobe (yellow and purple, respectively), bringing key catalytic residues, including those present in a critical $\alpha$ helix, $\alpha \mathrm{C}$, into position, converting the kinase into an active state that can now phosphorylate downstream substrates. (B) Close-up of phosphorylation-induced conformational changes in the activation loop. Two key residues in the activation loop of MAPKs, a threonine and a tyrosine residue, separated by a singe amino acid (i.e., a TXY motif) can interact with a network of surrounding arginine residues only when they are in their phosphorylated states. These interactions not only shift the positions of the threonine and tyrosine residues themselves (curved arrows), but drag the entire activation loop into a new conformation that communicates with the rest of the protein to move the entire amino-terminal lobe relative to the carboxy-terminal lobe, as shown in $A$.

transferase Tip60 (also known as Kat5) promotes recruitment of ATM to sites of DNA damage and ATM-dependent signaling. Similarly, microtubules containing acetylated tubulin are better able to recruit molecular motors that drive vesicular trafficking within the cell (Perdiz et al. 2011). As in the case of phosphorylation, acetylation is balanced by erasers, called deacetylases. Historically, histone proteins were thought to be the main targets of acetylation. Acetyl transferases and deacetylases are therefore commonly referred to as histone acetyltransferases (HATs) and histone deacetylases (HDACs), respectively. However, because neither of these classes of enzyme is specific for histone proteins, the terms lysine acetyltranferase (KAT) and lysine deacetylase (KDAC) are more appropriate.

Lysine and arginine residues can also be modified by methylation and/or demethylation (Fig. 3). Here, the amino acid side-chain nitrogen atoms have one or more of their hydrogen atoms replaced with methyl groups. A single lysine residue can contain one, two, or three methyl groups, whereas an arginine residue can contain one or two methyl groups distributed in different ways among the three sidechain guanidino nitrogens. Lysine methylation, like acetylation, can weaken interactions between histones and DNA (but can also lead to repression of transcription, depending on which histone lysine residue is methylated) and is therefore a major mechanism for the epigenetic control of gene expression. In addition, both lysine and arginine methylation can drive direct protein-protein interactions when the methylated lysine/arginine residues on one protein are recognized by modular domains of the Royal superfamily (e.g., Tudor, chromo, MBT, PWWP, and plant Agenet domains) on the other protein (Maurer-Stroh et al. 2003). For example, in response to DNA damage, kinases such as ATM and ATR phosphorylate a host of substrates to initiate cell-cycle arrest, DNA repair, and potentially cell death if the damage is too severe. One of these substrates 
M.J. Lee and M.B. Yaffe
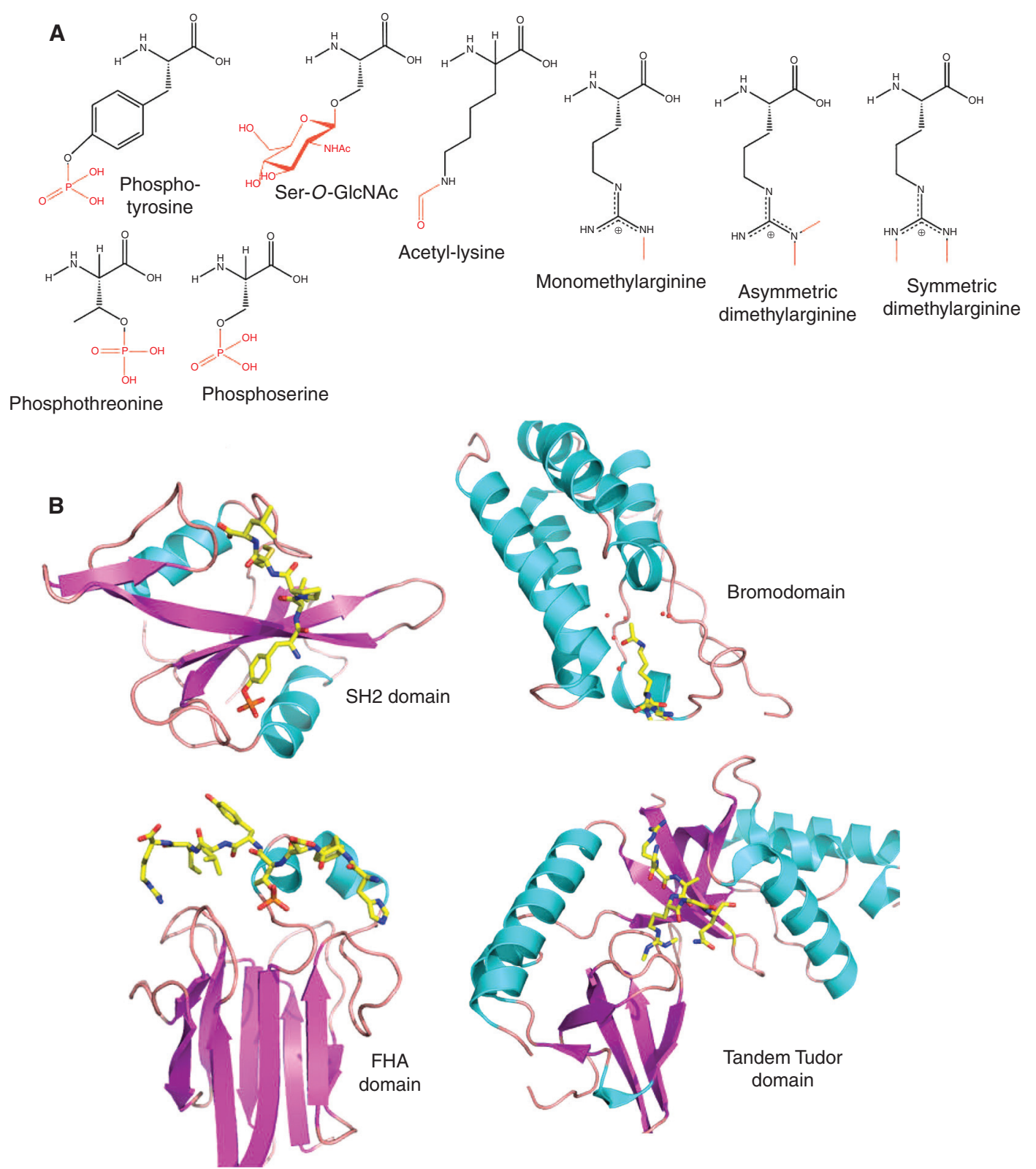

Figure 3. Examples of protein posttranslational modifications and modular protein-binding domains that recognize these modified amino acids. (A) Structures of common amino acid posttranslational modifications. The parent amino acid structure is shown in black; the modification is shown in red. (B) Cartoon representations of modular binding domains. $\alpha$ Helices are shown in cyan; $\beta$-strands are shown in purple; loops are shown in orange. $\mathrm{SH} 2$ domains recognize peptides containing phosphotyrosine, FHA domains recognize peptides containing phosphothreonine, Bromo domains recognize peptides containing acetyl-lysine, and Tandem Tudor domains recognize dimethylarginine. In the examples shown, the $\mathrm{SH} 2$ domain is from Src kinase, the FHA domain is from Chk2, the Bromo domain is from Brd4, and the Tandem Tudor domains are from SND1.

is the methyltransferase MMSET (also known as NSD2 or WHSC1). Phosphorylated MMSET is recruited to sites of DNA damage, where it methylates histone $\mathrm{H} 4$ on lysine residue K20. Methylated H4K20 recruits the DNA repair protein 53BP1 through a Tudor domain in 53BP1, facilitating DNA repair (Pei et al. 2011).
Other types of posttranslational modifications include glycosylation, nitrosylation, and nitration. Glycosylation occurs when sugar residues are covalently attached to the amide nitrogens of asparagine ( $N$-linked glycosylation) or to the hydroxyl groups of serine or threonine residues $(\mathrm{O}-$ linked glycosylation), usually as branched chains, in secret- 
ed proteins or the extracellular regions of transmembrane proteins. In most cases, these modifications help the protein to fold correctly or facilitate its transit and secretion, or insertion into the cell membrane; however, the addition of a single residue of a particular amino sugar- $\mathrm{N}$-acetylglucosamine-to serine and threonine residues of cytoplasmic proteins may function in some cases by preventing those same residues from being phosphorylated (Dias et al. 2012).

Protein nitrosylation involves the covalent incorporation of nitric oxide into the thiol side chain of cysteine residues within proteins, whereas protein nitration involves the incorporation of nitric oxide and/or its reactive nitrogen species onto the ring - $\mathrm{OH}$ group of tyrosine residues to generate nitrotyrosine. Three isoforms of nitric oxide synthase (NOS), the enzymes that produce NO, are known, all of which appear to participate in protein nitrosylation and nitration. Although less well understood than protein phosphorylation, both $S$-nitrosylation and $O$-nitration can also regulate protein structure, catalytic activity, stability, localization, and protein-protein interactions. Protein nitration appears to occur primarily as a consequence of oxidative stress and is believed to affect tissue homeostasis (Radi 2013). In contrast, protein thiol nitrosylation is emerging as a prominent mechanism for regulating signal transduction pathways, particularly those within the cardiovascular system (Lima et al. 2010). Although the bestknown role for NO in controlling vasodilation is through the generation of cGMP by activation of guanylyl cyclase (Newton et al. 2014), many of the effects of NO are mediated by $S$-nitrosylation. For example, the chemokine SDF1 induces cell migration and angiogenesis by activating endothelial NOS, which $S$-nitrosylates and inactivates the MAPK phosphatase MKP7 to enhance downstream signaling. One of the most intriguing targets of protein nitrosylation is small $G$ proteins of the Ras superfamily. Nitrosylation of a specific cysteine residue seems to facilitate their conversion from an inactive to an active form (see below) (Foster et al. 2009). Additional posttranslational modifications include ubiquitylation and lipidation (discussed in greater detail below).

\subsection{Noncovalent Regulation of Protein Activity}

Signals are not only transmitted in the form of protein posttranslational modifications. Ions, various lipids, and nucleotides can be produced or relocalized to function as second messengers that transmit a signal (Newton et al. 2014). Another major class of signaling enzymes is guanine-nucleotide-binding proteins, also called G proteins, a large family of signaling proteins that control a wide array of cellular functions, including motility, hormone responses, sensory perception, and neurotransmission. $G$ proteins function as molecular switches. Their activity is regulated by the intrinsic ability to bind and hydrolyze GTP to GDP.

In the basic GTPase cycle, G proteins exist in the "off" state bound to GDP (Fig. 4). G proteins have high affinity for GDP (and GTP); thus, the dissociation rates are very low. In addition, the nucleotide-free (i.e., empty) form of the protein is unstable, such that removal of GDP requires assistance from a guanine-nucleotide exchange factor (GEF). After dissociation of GDP, the empty G protein will favor binding to GTP because of the 10:1 ratio of GTP to GDP within the cell (Bos et al. 2007). The extra phosphate on GTP induces a conformational change in three switch regions near the nucleotide-binding pocket of the G protein, allowing substrate recognition. Signaling is promoted when $G$ proteins are in the active state through binding to motifs in other proteins that specifically recognize the GTP-bound conformation of the G protein. Although the GTP-bound G protein is generally the active state, capable of transducing downstream signals, in some systems, GDP-bound G proteins transduce the active signal, particularly in plants (Temple and Jones 2007). G proteins have a slow intrinsic GTPase activity $\left(k_{\mathrm{cat}}=10^{1}-10^{-3}\right.$ $\min ^{-1}$ ) that results in GTP hydrolysis and returns the protein to the "inactive" GDP-bound state; however, the rate of GTP hydrolysis can be dramatically enhanced (by a factor of $10^{3}-10^{6}$ ) by interaction with GTPase-activating proteins (GAPs). Another important class of regulators is guaninenucleotide dissociation inhibitors (GDIs). These bind to and stabilize the inactive GDP-bound state, maintaining the $G$ protein in the inactive conformation. Thus, coordinated actions of GEFs, GAPs, and GDIs are critical factors in determining the amplitude, dynamics, and duration of G-protein-transduced signals. The two major classes of $G$ proteins are small $G$ proteins and heterotrimeric $\mathrm{G}$ proteins.

\subsubsection{Small G Proteins}

Small G proteins are $\sim 20-25 \mathrm{kDa}$ in size and consist of a single monomeric subunit that has nucleotide binding and GTPase activities. More than 100 small G proteins exist in humans. The prototypic small $G$ protein is Ras; thus, this class of proteins is sometimes referred to as the Ras superfamily. At least 10 distinct subfamilies exist within the Ras superfamily. Members within a single subfamily generally share similar sequence, structure, and functions (Wennerberg 2005). For example, members of the Rho subfamily (which include RhoA, Rac1, and Cdc42) are generally involved in cytoskeletal dynamics and cell morphology, whereas members of the Arf subfamily control vesicular transport. Targets for small $\mathrm{G}$ proteins are often themselves signaling proteins, which creates signaling cascades. For 


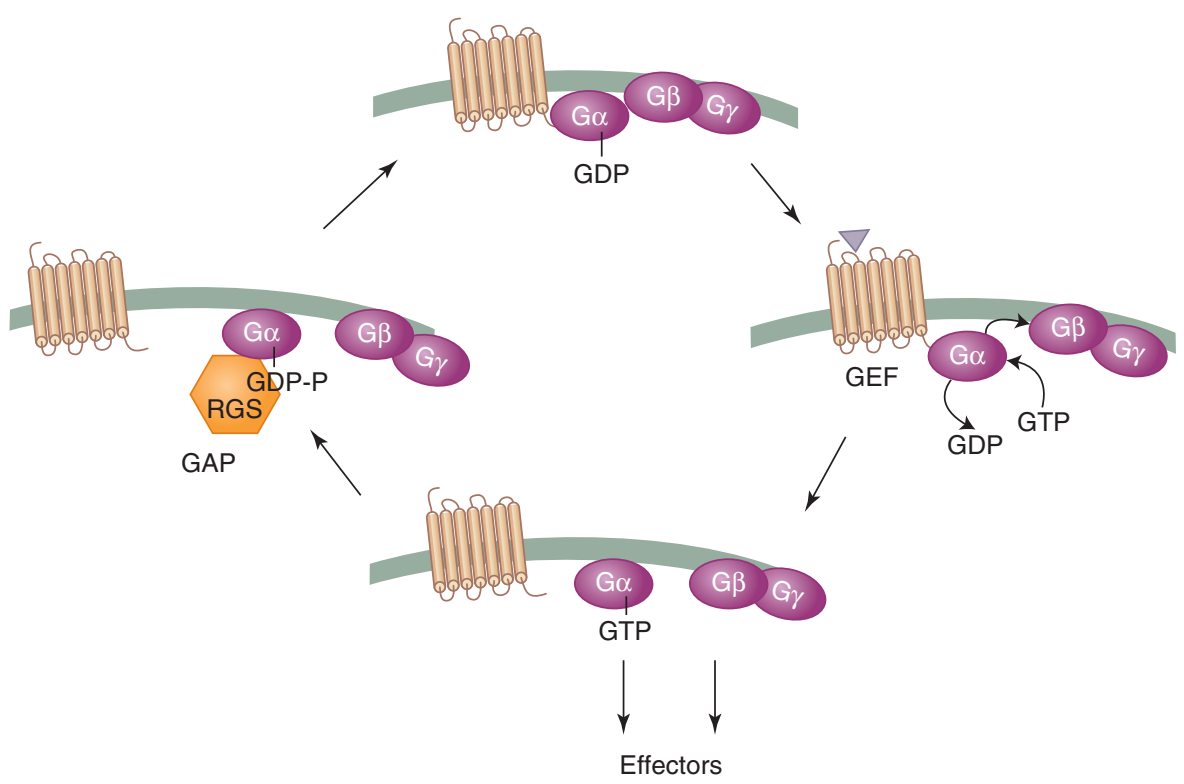

Figure 4. The GTPase cycle. G proteins can be small (Ras-like) or large (heterotrimeric). Depicted here is the nucleotide cycle for heterotrimeric $\mathrm{G}$ proteins, but the reactions are conceptually the same for small GTPases. Gprotein-coupled receptors (GPCRs) bind extracellular ligands, and transmit signals to intracellular G proteins. The ligand-bound receptor functions as a guanine-nucleotide exchange factor (GEF), causing the G $\alpha$ subunit to exchange GDP for GTP. GTP-bound G $\alpha$ no longer interacts with the G $\beta \gamma$ dimer, and both entities are free to interact with downstream effector proteins. G $\alpha$ controls the duration of the signal because it is a GTPase, whose activity can be stimulated by GTPase-activating proteins (GAPs) such as RGS proteins.

example, Ras activates the kinase Raf, and Rho activates the kinase ROCK.

The characteristics, mechanisms of action, and regulation of GEFs, GAPs, and GDIs differ between small G proteins and heterotrimeric $G$ proteins. GEFs for small $G$ proteins differ in structure and domain architecture for each of the Ras subfamilies, but their mechanisms of action generally involve interaction with the so-called switch regions of the GTPases and the coordination of a magnesium ion within the nucleotide-binding pocket (Sprang 1997). Small G proteins typically have only marginal GTPase activity (often 100-fold to 1000-fold slower than the $\mathrm{G} \alpha$ subunits of heterotrimeric $\mathrm{G}$ proteins). GAPs for this class of protein contain a catalytic "arginine finger" region that inserts into the binding pocket, greatly increasing the rate of hydrolysis (Kötting et al. 2008). GDIs generally stabilize the inactive state, but may also alter membrane association or stabilize the GTP-bound state. Members of the Ras subfamily-particularly H-Ras, K-Ras, and N-Ras-are important in many types of cancer because they control cell proliferation (see Sever and Brugge 2014). Two constitutively active mutations are commonly seen in various cancers, including lung, colon, and pancreas. Mutation of the phosphate-binding loop glycine (G12) to valine or aspartic acid results in loss of sensitivity to GAPs, resulting in a prolonged activation period and a higher basal level of signaling. Mutation of the catalytic glutamine residue (Q61), which normally coordinates a water molecule that attacks the $\beta-\gamma$ bond in GTP to a leucine, results in an enzymatically inactive protein because the enzymatic transition state cannot be stabilized (Privé et al. 1992).

\subsubsection{Heterotrimeric G Proteins}

The second class of $G$ proteins is heterotrimeric $G$ proteins, which function downstream from G-protein-coupled receptors (GPCRs) (Hepler and Gilman 1992; Heldin et al. 2014). The GTPase in this system is the Ga subunit. Roughly 20 different $G \alpha$ subunits exist in humans, each of which contains two main domains: a GTPase domain that has sequence and structural similarity to Ras (also called the Ras-like domain) and an $\alpha$-helical domain that can be posttranslationally modified and contributes to GTPase regulation (Dohlman and Jones 2012). The other components of the heterotrimer are the $G \beta$ and $G \gamma$ subunits, which generally exist as an obligate dimer. In the basal state, $\mathrm{G} \alpha$ and $\mathrm{G} \beta \gamma$ form a tripartite complex in which $\mathrm{G} \alpha$ is bound to GDP; however, the ligand-bound GPCR induces a conformational change in $\mathrm{G} \alpha$, resulting in GDP-for-GTP exchange. In the GTP-bound state, $G \alpha$ and $G \beta \gamma$ dissociate, and each is able to transduce a signal to downstream effector proteins. The GEFs for heterotrimeric $G$ proteins are 
typically the GPCRs themselves (Weis and Kobilka 2008). Some non-GPCR GEFs have been identified, including Ric8a, Arr4, and various AGS family proteins, but their roles are still unclear. G $\alpha$ subunits have GTP hydrolysis rates about 100 times higher than the Ras superfamily, but GAPs targeting them nevertheless exist. These proteins each contain a regulator of G-protein-signaling (RGS) domain. Some RGS proteins, like Sst2 in yeast or RGS2 and RGS4 in mammals, are relatively simple, essentially containing only an RGS box; others are more complex, containing numerous functional domains (Siderovski and Willard 2005). Unlike GAPs for small G proteins, RGS proteins function by interacting with the switch regions on $\mathrm{G} \alpha$, and stabilizing the transition state between GDPand GTP-bound forms (Tesmer et al. 1997).

\subsubsection{The GPCR GEF Reaction}

It has been estimated that $30 \%-50 \%$ of all drugs target GPCRs or some aspect of GPCR-mediated signal transduction (Wise et al. 2002). Despite this, our understanding of how GPCRs activate $\mathrm{G}$ proteins remains incomplete. Unlike GEFs for small GTPases, GPCRs do not make contact with the switch regions on $\mathrm{G} \alpha$. Furthermore, other than the mobile switch regions, the $\mathrm{G} \alpha$ subunit was not thought to undergo large conformational changes upon activation. Recent high-resolution crystal structures of a GPCR-heterotrimeric G-protein-ternary complex, however, indicate that binding of ligand to the GPCR may induce a major displacement of the all-helical domain of $\mathrm{G} \alpha$ relative to the Ras-like GTPase domain during catalysis (Chung et al. 2011; Rasmussen et al. 2011). These structures suggest a mechanism by which binding of ligand to a GPCR induces nucleotide exchange.

\section{REGULATION OF PROTEIN-PROTEIN INTERACTION}

\subsection{Protein Interaction Domains}

What exactly is a protein domain, and what kind of amino acid sequences do reader domains involved in proteinprotein interactions read? A domain is a segment of a protein, generally 50-400 amino acids in length, that folds independently into a stable three-dimensional structure and is capable of some type of independent function. Most signaling proteins are built of multiple domains. The sequences that connect the domains together are usually short and less structured parts of the protein. More than 1000 modular protein domains have been characterized using bioinformatics (Letunic et al. 2011).

A classic example of modular protein reader domains is $\mathrm{SH} 2$ domains, which bind to phosphotyrosine-containing sequences. Another example is $\mathrm{SH} 3$ domains, which bind to proline-containing sequences. Other domains, such as PTB domains, HYB domains, and some C2 domains, can also bind to phosphotyrosine-containing sequence motifs, whereas WW, EVH1, and GYF domains, like SH3 domains, bind to short proline-rich sequences.

A wide variety of domains recognize other posttranslational modifications. Domains such as $14-3-3$, FHA domains, tandem BRCT domains, $\mathrm{MH} 2$ domains and Polo-box domains, for example, bind to short phosphoserine- and/or phosphothreonine-containing motifs (Yaffe and Smerdon 2004). Bromo domains recognize specific acetyl-lysine-containing sequences, and chromodomains, Tudor domains, MBT domains, and PWWP domains bind to sequences that contain methyl-lysine and methylarginine. Other domains, such as CUE, PAZ, UBA, and UEV domains, can bind to ubiquitin or specific types of ubiquitin chains. The ability of these domains to distinguish unmodified proteins from proteins containing these different types of posttranslational modifications ensures that protein-protein interactions occur only when one of the two proteins has been appropriately marked and modified by a writer. This use of readers allows protein-protein interactions and the assembly of multiprotein signaling machines, or even the activity of a single protein, to be precisely controlled by the actions of writers and erasers in response to a signal. For domains like $\mathrm{SH} 3$ domains that do not bind to modified sequences, their reader functions are typically regulated by conformational changes in other parts of the protein that modulate access of the domain to binding partners.

Reader domains are often found within proteins that also contain writer or eraser domains. Frequently, these interact with each other or with sequences that lie outside the domain, and this can have important functional consequences. This is perhaps best illustrated by the tyrosine kinase Src. Src contains a kinase writer domain, together with $\mathrm{SH} 2$ and $\mathrm{SH} 3$ reader domains. In the inactive state, the $\mathrm{SH} 2$ domain of Src is bound to a carboxy-terminal tyrosine residue that has been phosphorylated, while its $\mathrm{SH} 3$ domain is bound to a proline-containing linker region between the $\mathrm{SH} 2$ domain and the kinase domain. In this conformation, the $\mathrm{SH} 2$ and $\mathrm{SH} 3$ domains rest against the back surface of the kinase domain, holding it in a catalytically inactive form. Dephosphorylation of the carboxyterminal tyrosine in Src by phosphatases such as SHP1 or SHP2, or displacement of the $\mathrm{SH} 2$ and $\mathrm{SH} 3$ domains through competitive binding to phosphotyrosine sequences (such as those found in platelet-derived growth factor receptor [PDGFR]) or focal adhesion kinase (FAK) and polyproline sequences (such as those found in the arrestin-bound $\beta 2$ adrenergic receptor, NEF, or Sin) then releases 
the kinase domain to promote activation. Together with phosphorylation of a tyrosine residue in the activation loop, this results in full catalytic activity (Fig. 5).

A similar intramolecular interaction between reader and writer domains keeps the mitotic kinase Polo-like kinase 1 (Plk1) inactive until a certain level of cyclin-dependent kinase (CDK) activity has been reached (Rhind and Russell 2012). Plk1 contains an amino-terminal kinase writer domain and a carboxy-terminal Polo-box reader domain that fold back against each other in interphase cells to keep the protein inactive (Lowery et al. 2005). When cells approach mitosis, CDKs phosphorylate substrates such as Cdc25C and Wee1 to generate phosphoserine/threonine motifs that can bind directly to the Polo-box domain, prying it away from the kinase domain. Again, together with phosphorylation of a threonine residue in the activation loop, this drives Plk1 into the fully active form required for cells to complete mitosis.

For many domains, portions that are not directly involved in motif recognition can also be instrumental in stabilizing protein-protein interactions. These types of domain-domain interactions are often important in assembly of multisubunit signaling complexes. For example, non-ligand-binding portions of the $\mathrm{SH} 2$ domain in phospholipase Cy (PLC $\gamma$ ) are used to stabilize interactions with fibroblast growth factor 1 (FGFR1). Intriguingly, evo- lution has led to preferential cosegregation of particular protein domains within individual proteins (Jin and Pawson 2012). For example, SH2 domains and SH3 domains frequently co-occur, as do PX domains and $\mathrm{SH} 3$ domains. Presumably this is because specific combinations of domains have already mastered the molecular origami required for both productive interactions and allosteric control over additional domains with which they coassociate (see Table 1 for common domains, their partners, and motifs).

\subsection{Motifs}

For readers, writers, and erasers to function together to form signaling networks, they must operate on common short amino acid sequence motifs in their targets. Most such motifs contain $\sim 15$ amino acid residues and include particular amino acids that confer specificity to the writers and readers. For example, CDKs and MAPKs (writers) preferentially phosphorylate S-P and T-P motifs, whereas Polobox domains (readers) preferentially recognize motifs with the consensus S-pS/pT-P (where pS and pT are phosphorylated serine and threonine). Similarly, many tyrosine kinases (writers) phosphorylate tyrosine residues that are surrounded by acidic amino acid residues, whereas $\mathrm{SH} 2$ domains (readers) prefer bind to phosphotyrosine-con-

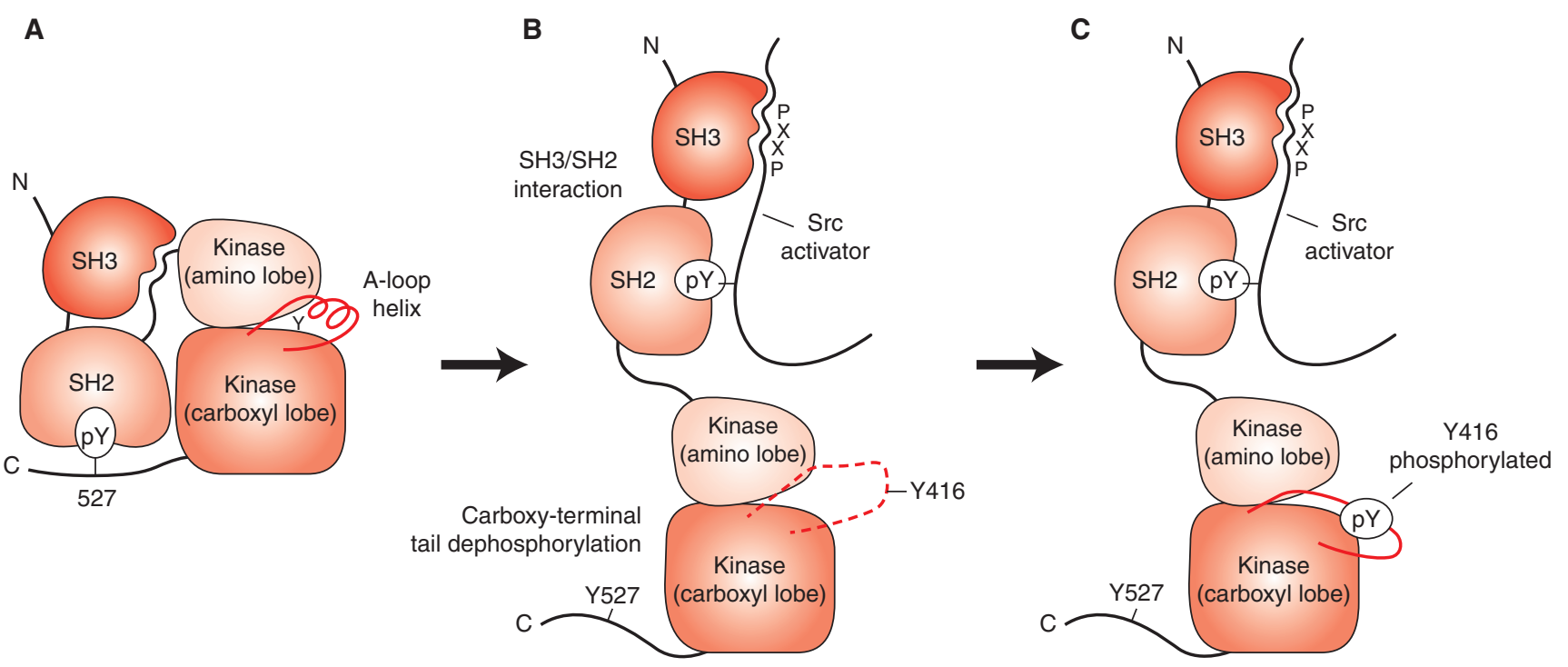

Figure 5. A multistep mechanism for maximal Src activation. (A) In the inactive state, Src is folded up as a consequence of multiple interactions between the reader domains and motifs in Src itself. The Src SH2 domain is bound to a phosphotyrosine residue (Y527) in the carboxyl terminus, while the SH3 domain binds to a polyproline-type helix in the linker that connects the $\mathrm{SH} 2$ domain to the kinase domain. (B) The kinase opens up into an active conformation when a ligand such as a growth factor receptor or an adaptor protein engages the $\mathrm{SH} 2$ and $\mathrm{SH} 3$ domains directly, usually accompanied by dephosphorylation of the Y527 site to prevent intramolecular reassociation into the closed form. (C) Autophosphorylation of Y416 in the activation loop of Src, or phosphoprylation of this site by another kinase, results in maximal activity. (From Xu et al. 1999; adapted, with permission, (C) Elsevier.) 
taining sequences that contain specific patterns of hydrophobic or small amino acid residues carboxy terminal to the phosphotyrosine. Some domains can bind multiple sequence motifs or even bind ligands in multiple orientations, as is the case for SH3 domains and SUMO-SIM domains.

This type of limited overlap between the sequences that the writer domains generate and those that the reader domains recognize gives rise to the specificity we observe in signaling networks. That is, only a small fraction of the targets of any particular writer are then recognized by a particular reader. As mentioned above, not all motifs require posttranslational modification (e.g., proline-rich sequences are recognized by $\mathrm{SH} 3$ domains, WW domains, and EVH1 domains, among others), which leads to competition between a motif and multiple readers, depending on localization and timing. In contrast, some types of domains appear to recognize specific combinations of posttranslational modifications. Some bromo domains, for example, recognize specific phosphoacetylmethyl motif combinations on histones (Filippakopoulos et al. 2012), whereas $14-3-3$ proteins are able to recognize both phosphorylated and phosphoacetylated histone sequences (Macdonald et al. 2005). A similar effect can be achieved by adjacent protein-protein interaction domains that bind to different posttranslational modifications. These domains or domain combinations function as readers of a more complex code, essentially creating "AND gates," which can be used to dictate greater specificity and control, or functioning as integrators of signaling from multiple pathways.

Because most motifs are defined by the primary structure of a protein rather than a complicated 3D arrangement of noncontiguous elements, it is a relatively straightforward process to go motif hunting using protein sequences and bioinformatics search tools (Obenauer et al. 2003; Obenauer and Yaffe 2004). The small, "portable" nature of these motifs means that they have frequently moved around within the sequences of evolutionarily related proteins. Thus, a motif can sometimes be seen in one part of a protein sequence in a human protein and in another part of the sequence in a yeast ortholog.

\section{REGULATION OF PROTEIN LOCATION}

Signaling processes occur in the context of the multicompartment, 3D environment of the cell. Information transfer from the cell exterior, across lipid membranes, and through/within the cytosol must be tightly regulated in both space and time, and a key component to achieving specificity is the dynamic regulation of protein localization.

\subsection{Compartmentalization}

A common theme in signaling is modulating compartmentalization of signaling proteins within the cell. This can dictate access to substrates or environmental conditions that promote activation. Subcellular compartments, particularly organelles and cytoskeletal structures, can be very dynamic. In these cases, signaling can promote the formation of these compartments. The spatial segregation that organelles provide represents an important layer of regulation, allowing similar proteins to execute different functions in different environments. For example, mitotic kinases like Plk1, Aurora B, and Never in mitosis kinase 2 (Nek2) achieve substrate specificity through nonoverlapping subcellular localization, despite sharing partially overlapping substrate selection motifs (Alexander et al. 2011).

Such compartmentalization can be achieved in different ways. Some proteins have short sequences (also called signal peptides) that function as localization signals, allowing transport to a particular organelle. The best recognized of these are nuclear localization signals (NLSs), which typically feature one or more short sequences of positively charged lysine or arginine residues (Hung and Link 2011). Similar signals have been identified for many other organelles, including mitochondria, lysosomes, and peroxisomes. For proteins with localization sequences, regulated localization can be achieved through posttranslational modifications or conformational changes that mask or unmask a signal peptide. Type I nuclear receptors, for example, are typically retained in the cytoplasm in an inactive complex with HSP90 (see Sever and Glass 2013; Heldin et al. 2014). Ligand binding induces a conformational change, dissociation of HSP90, homodimerization, and active transport into the nucleus, promoting DNA binding and gene expression. Phosphorylation of the MAPK ERK on an SPS motif within the kinase-insert region results in recognition by the nuclear transport receptor importin $\beta 7$ (Chuderland et al. 2008). Following nuclear import, ERK then phosphorylates nuclear substrates, including transcription factors Fos, Myc, and Elk1 (see Morrison 2012). For proteins without localization sequences, protein-protein interactions or association with lipid membranes can localize them to specific subcellular regions.

\subsection{Membrane Localization}

Attachment to various cellular membranes can function as an anchor that restricts a protein or its activation to certain subcellular areas. Another benefit is that signaling is more efficient in two dimensions, because the local concentration near the membrane is greatly increased. Some estimates have suggested that membrane association increases the local protein concentration as much as 1000 -fold (McLaughlin 
and Aderem 1995). Membrane-localized proteins can be either transmembrane proteins embedded in the membrane or peripheral membrane proteins that attach to membranes through protein-lipid interactions. Because they connect two physically separated environments, transmembrane proteins are well positioned to function as pumps, ion channels, or cell-surface receptors (Heldin et al. 2014). Peripheral membrane proteins, which may interact with transmembrane receptors, typically function as signaling intermediaries. The most common method of membrane attachment for these proteins is through the covalent attachment of lipid groups (e.g., glycophosphatidylinositol [GPI] anchors and other lipid chains) (Casey 1995; Nadolski and Linder 2007) and reversible recruitment to the plasma membrane is a common method of signal regulation. Upon activation of certain receptor tyrosine kinases, for example, phosphoinositide 3-kinase (PI3K) is recruited to the receptor via interactions between the $\mathrm{SH} 2$ domains of the $\mathrm{p} 85$ subunit of PI3K and phosphorylated tyrosine residues on the activated receptor. Active PI3K then phosphorylates phosphatidylinositol 4,5-bisphosphate $\left(\mathrm{PIP}_{2}\right)$ to create phosphatidylinositol-3,4,5-trisphosphate $\left(\mathrm{PIP}_{3}\right)$. Downstream effectors like the kinase Akt then are recruited to the membrane through a $\mathrm{PH}$-domain-dependent interaction with $\mathrm{PIP}_{3}$. Once at the membrane, Akt can then be phosphorylated and activated by its activating kinase PDK1, which also has a $\mathrm{PIP}_{3}$-binding $\mathrm{PH}$ domain. Similar mechanisms in which subcellular localization and activation are intrinsically coupled are also used for activation of Ras family GTPases. These involve recruitment of activation factors such as GEFs to the plasma membrane.

\subsection{Lipid Modification}

Membrane attachment can be induced by protein lipidation, owing to the hydrophobicity of the modifying lipid.
Many types of lipid modification exist, each unique in its regulation, chemical properties, and mechanism of linkage to proteins (Fig. 6). Myristoylation is the cotranslational addition of a saturated 14-carbon acyl chain to an aminoterminal glycine. The myristoyl moiety has a relatively low level of hydrophobicity. Thus, myristoylated proteins, such as Src-family kinases and some G proteins, typically achieve membrane attachment by using myristoylation in concert with other lipid modifications or nearby polybasic amino-acid stretches. Myristoylation can allow proteins to attach to membranes, but, in some cases, it alters protein conformation or protein-protein interaction (Boutin 1997). A myristoyl group added to the C subunit of PKA, for example, can insert into a lipid a bilayer, promoting membrane localization, or alternatively, fold into a hydrophobic pocket of the enzyme, allowing regulation of the protein-lipid conformational state by phosphorylation. Another common modification is prenylation, the posttranslational addition of a 15-carbon farnesyl or 20-carbon geranylgeranyl chain attached to a carboxy-terminal cysteine. The enzymes responsible for prenylation have been identified, and inhibitors of these enzymes have received much attention as anticancer agents, owing to the importance of prenylation of GTPases in the Ras family (Resh 2012).

Another example is palmitoylation, the addition of a 16-carbon-chain fatty acid to cysteine residues through a thioester bond. Protein subcellular localization is often dictated by palmitoylation, through the localization of the palmitoyl acyltransferase (PAT). For example, proteins with only a myristoyl or prenyl group are thought to transiently interact with membranes, sampling many membrane surfaces within the cell. However, palmitoylation of a singly lipid-modified protein induces stable membrane attachment. Thus, through limited spatial expression of the PATs, palmitoylation can dictate protein subcellular

Myristoylation
$\begin{aligned} & \text { Prenylation } \\ & \text { Farnesylation } \\ & \text { Geranylgeranylation }\end{aligned}$

Figure 6. Common forms of protein lipidation. The table highlights four lipid moieties that are commonly used to modify proteins posttranslationally or (in the case of myristoylation) cotranslationally. These modifications differ in terms of their consensus sequences, position of the modification, hydrophobicity, and mechanism of regulation. 
localization. For example, the Ras family member H-Ras can localize to the plasma membrane or Golgi apparatus, having unique signaling roles at each location. H-Ras subcellular localization is dictated by palmitoylation on one of two carboxy-terminal cysteine residues (Roy et al. 2005). Furthermore, unlike myristoylation or prenylation, palmitoylation is a reversible process and can be dynamically regulated during signal transduction.

\subsection{Membrane Microdomains and Spatially Restricted Signaling}

Proteins and lipids in the plasma membrane are thought to be distributed heterogeneously, forming membrane microdomains (Maxfield 2002). This may help sequester lowabundance molecules, increasing their local concentrations or facilitating the formation of signaling machines. Examples of such microdomains include invaginations of the plasma membrane called caveolae and lipid rafts, cholesterol- and sphingolipid-rich portions of the membrane that potentially function as organizing centers for compartmentalized signaling. GPI-linked proteins are preferentially localized to such microdomains, which may play an important role in many signaling processes. Membrane microdomains can be used to promote spatially restricted signaling, such as those seen in the immunological synapse (the interface between an antigen-presenting cell and effector T cell) (see Cantrell 2014).

Spatially regulated signal transduction is a well-established phenomenon, but an emerging paradigm is the positive and negative regulation of plasma-membraneassociated signals at intracellular locations. For example, H-Ras, well known to transduce signals from the plasma membrane, also exists at Golgi bodies, where it transmits a unique signal (Bivona et al. 2003). In addition, a growing body of evidence supports a positive role for the endocytic pathway in signal transduction (Zastrow and Sorkin 2007; Murphy et al. 2009). Numerous signals transmitted from endosomal locations have been identified, including those coupled to RTK- (Di Guglielmo et al. 1994) and GPCRcoupled signals (Lefkowitz and Shenoy 2005; Slessareva et al. 2006).

Signals can also be spatially restricted through binding to protein scaffolds. The co-occurrence of multiple motifs on a single molecule can lead to the formation of signaling scaffolds and signaling hubs. If a single protein contains multiple motifs and each is recognized by a different protein, then these will all converge. Such an arrangement is used, for example, to organize MAPK signaling in yeast and mammalian cells (Elion 2001; Engström et al. 2010; Morrison 2012). By using scaffolds to bring two or more proteins together, cells overcome the diffusion problem and no longer require the proteins to find each other in the crowded interior of the cell. As is the case for membrane attachment, the tethering of proteins to scaffolds greatly increases the effective concentration of signaling proteins. If the different proteins that are recruited to a multimotif protein do not communicate directly with each other, but instead act on other proteins, then the multimotif protein serves as a hub, where multiple signaling events converge in time and space. Such an arrangement is used, for example, by Akinase-anchoring proteins (AKAPs) to coordinate signaling through PKA pathways (Newton et al. 2014), and by the cytoplasmic tails of growth factor receptors to coordinate signaling by Ras, PI3K, PKC, and MAPKs (Heldin et al. 2014).

\section{REGULATION OF PROTEIN PRODUCTION}

At its most basic level, signaling is controlled by the relative stoichiometry of positive and negative signaling intermediaries, which are frequently proteins. Any process that changes the balance of these proteins can, in turn, modulate the signal. One basic and widely used strategy is to change how much of the signaling intermediate-whether a ligand, second messenger, or protein-is available to transmit information. Cells use an incredibly diverse array of methods to regulate protein levels-so many, in fact, that an in-depth review of this topic would be a textbook unto itself. Here, we therefore focus on basic ways cells control signaling by modulating the rate of protein synthesis or protein degradation. The processes that can be targeted include transcription, RNA stability, RNA splicing, and translation. Of these, transcriptional regulation is probably the best studied and most commonly recognized target of signal transduction pathways.

\subsection{Transcriptional Control}

The output of many signaling pathways is transcription of genes that encode proteins necessary for the desired cellular response. The regulation can occur by modulating nuclear localization of transcription factors, coactivators, and other regulatory proteins by modulating the DNAbinding capabilities of these proteins or by posttranslationally modifying histones to modulate chromatin architecture. A good example is the transcriptional control of the tumor suppressor p53, which is a transcription factor, and its downstream targets in response to DNA damage signals (Brown et al. 2009; Duronio and Xiong 2013). In unstressed cells, p53 expression remains low, owing to a low level of transcription and constitutive ubiquitin-dependent degradation of p53 promoted by an E3 ligase protein called MDM2 (Momand et al. 1992). In response 
to various cellular stressors, including ionizing radiation, UV, and other forms of genotoxic damage, the transcription of the p53 gene is dramatically increased, and the p53 protein is phosphorylated on one or more of its many phosphorylation sites. There are two important consequences of this phosphorylation event. The first is increased levels of $\mathrm{p} 53$ protein due to loss of interaction with MDM2, an E3 ubiquitin ligase that drives ubiquitinmediated degradation (see below) of p53 in unstimulated cells. Second, as a result of MDM2 dissociation, p53 undergoes a conformational change that allows it to interact with DNA and drive transcription of new p53 target genes. Among the genes activated by p53 are those that control cell-cycle arrest, DNA repair, and apoptotic cell death, and even the p53 gene itself (Bieging and Attardi 2012).

\subsection{RNA Stability and miRNAs}

Signal transduction can also involve modulation of mRNA processing or stability. Several splicing factors are phosphorylated in response to signaling, and these events may control alternative splicing of pre-mRNAs to give different mRNA isoforms (Lynch 2007). Cells can regulate mRNA stability by modulating mRNA maturation (via $5^{\prime}$ capping or $3^{\prime}$ polyadenylation) or interactions between RNA-binding proteins and mRNA transcripts (Wu and Brewer 2012). An emerging area of research is the control of signaling by cellular micro-RNAs (miRNAs) and other noncoding RNAs, such as long noncoding RNAs (lnc-RNAs). miRNAs are short ( $\sim 21-23$ nucleotide) untranslated RNAs (Ambros 2001) that typically induce degradation of target RNAs or block mRNA translation through sequence-specific base-pairing interactions. They are important regulators of normal developmental timing (Ambros 2011). miRNAs like Lin-4/ mir-125 regulate the temporal transitions between pluripotent and differentiated states of numerous stem cell populations.

miRNAs are also common regulators of the dynamics, duration, and sensitivity of signaling processes. Many signaling pathways-including the Wnt, Notch, Hedgehog, and p53 pathways, for example-achieve specificity and sensitivity through active repression (i.e., basal repression or default repression). In this context, miRNAs target core pathway components or their transcriptional targets, maintaining cells in the inactive state, causing the system to require greater levels of stimulus for activation and also sharpening the response to activating stimuli. For example, miR-125 targets many components of p53 signaling, and loss of miR-125 causes spontaneous p53 activation.

\subsection{Translational Control}

Translation is also a target of signal transduction pathways. For example, the mammalian target of rapamycin (mTOR) and related pathways are now well known to control protein translation in response to nutrient, growth factor, and amino acid signals (Laplante and Sabatini 2012). A critical target involved in the regulation of translation by the mTORC1 complex is the eukaryotic translation initiation factor 4E (eIF4E)-binding protein 1 (4E-BP1) (Hara et al. 1997). 4E-BP1 inhibits cap-dependent translation by binding to eIF4E, the initiation factor that recognizes the $5^{\prime}$ cap on mRNA molecules. Phosphorylation of 4E-BP1 at T37 or T46 is thought to prime $4 \mathrm{E}-\mathrm{BP} 1$ for subsequent phosphorylation at $\mathrm{S} 65$ and T70, leading to loss of interaction with eIF4E (Gingras et al. 1999), which results in a general increase in protein translation. The mTORC1 complex also regulates the activity of p70 S6 kinase 1 (S6K1), which has many targets whose phosphorylation activates translation (Pullen and Thomas 1997). Key among these is the S6 subunit of the $40 \mathrm{~S}$ ribosome, which when phosphorylated by $\mathrm{S} 6 \mathrm{~K} 1$ promotes increased translation of mRNA transcripts containing an oligopyrimidine sequence in their $5^{\prime}$ untranslated region (5'-UTR). Additionally, translation of specific mRNAs can be controlled through feedback signaling at the level of translation initiation. For example, iron homeostasis is maintained in part by regulating the translation of proteins involved in iron import. In the presence of high concentrations of intracellular iron, the transferrin receptor mRNA is repressed by ironinduced binding of iron-response-element-binding protein (IREBP) to a $5^{\prime}$-UTR element in the transferrin receptor mRNA.

\section{PROTEIN DEGRADATION}

Every protein has a baseline level of expression resulting from the equilibrium between its synthesis and breakdown (see Box 1). A control mechanism widely used in signal transduction is regulation of the rate of protein degradation. Many methods exist for regulated degradation of proteins, including lysosomal and ER-mediated degradation (Ciechanover 2012), but the mechanism that seems to be most important in cell signaling is ubiquitin-dependent proteasomal degradation (Hershko and Ciechanover 1998). Ubiquitin is a small 76-amino-acid protein that can be conjugated through its carboxyl terminus to lysine residues on target proteins or to other ubiquitin molecules to form ubiquitin chains that serve as a marker for various cellular functions. Through diversity in chain length or the orientation of chain attachment, ubiquitin can regulate protein trafficking and protein-protein interactions, or 


\section{BOX 1. PROTEIN LEVELS DESCRIBED MATHEMATICALLY}

Protein levels are best described using a deceptively simple equation:

$$
d[\mathrm{P}] / d t=k_{1}-k_{2}[\mathrm{P}],
$$

where $[\mathrm{P}]$ is the protein concentration, $k_{1}$ is the synthesis rate, and $k_{2}$ is the degradation rate. Obviously, $k_{1}$ and $k_{2}$ reflect complex processes that are themselves regulated by signaling events at multiple levels. At steady state, when $[\mathrm{P}]$ is constant, $d[\mathrm{P}] / d t=0$ and $[\mathrm{P}]=k_{1} / k_{2}$. Therefore, to increase $[\mathrm{P}]$, we need either to increase the synthesis rate or to decrease the degradation rate. The two key questions from a biologist's point of view are these: (1) what will the new level be? and (2) how fast will the changes happen-that is, how long until the new steady-state level is reached? Consider the case when the synthesis of a protein ceases entirely-that is, $k_{1}=0$. Because the protein is now subject only to degradation, the new steadystate level will be 0 - that is, $[\mathrm{P}]=0 / k_{2}$-but the rate of decline is given by $k_{2}$; that is, $t_{1 / 2}=\ln 2 / k_{2}$. The somewhat surprising thing is that the same is true if we change the synthesis rate to some value other than zero. For example, if we double the synthesis rate, the new steady-state level will be twice the old steadystate level $\left(\left[\mathrm{P}_{\mathrm{ss}}\right]=k_{1} / k_{2} \rightarrow 2 k_{1} / k_{2}\right)$, but the time it takes to reach the new steady-state level will be determined not by the change in synthesis rate but by the degradation rate, $k_{2}$. Thus, big changes in synthesis rate only cause rapid changes in steady-state protein levels if the degradation rate is fast, that is, if the protein is short lived. Similarly, minor changes in degradation rates are manifest with kinetics that depend not on the degradation rate but the synthesis rates-that is, rapid changes in degradation rate only manifest in changes in steady-state protein levels if the synthesis rate is fast.

function as a signaling scaffold (Muratani and Tansey 2003; Kirkin and Dikic 2007; Walczak et al. 2012).

Perhaps its major role, however, is to form polyubiquitin chains that target proteins for destruction by the proteasome. Recognition by the proteasome requires at least four ubiquitin monomers linked to each other through amide bonds involving the carboxyl terminus of one ubiquitin molecule and $\mathrm{K} 48$ on another ubiquitin molecule. Although chains of four monomers are required, longer chains are typical, presumably increasing the efficiency of proteasomal recognition. Ubiquitin chains are formed through a cascade of enzymatic processes performed by a ubiquitin-activating protein (E1), a ubiquitin-conjugating protein (E2), and a ubiquitin ligase (E3) (Fig. 7). The chains target proteins to the proteasome, a large protein complex containing multiple proteolytic enzymes, where ubiquitylated proteins are subsequently degraded and their parts recycled by the cell. A classic example of this process in action is the regulated expression of the cyclin proteins (Rhind and Russell 2012), whose oscillating levels allow the periodic activation of cyclin-dependent kinases (CDKs) that regulates progression through the cell cycle (Malumbres and Barbacid 2005). These oscillations are achieved primarily by increased degradation of cyclins by ubiquitin-dependent proteasomal degradation, coupled with increased cyclin synthesis at different points in the cell cycle (Sudakin et al. 1995).

Other types of polyubiquitin chains, in which the individual ubiquitin molecules are connected through amide bonds involving residues in ubiquitin other than K48 can also be added to proteins (Fig. 7) (Ikeda and Dikic 2008). Seven such chain types can be formed, in which the lysine side-chain amino group in one of the seven lysine residues present in ubiquitin is linked to the carboxy-terminal diglycine motif of the next ubiquitin molecule through an isopeptide bond. Prominent examples of these other ubiquitin chains in signaling include the use of K63-linked chains to control protein-protein interaction rather than protein degradation. In the IKK/NF- $\mathrm{BB}$ pathway (see Lim and Staudt 2013), for example, stimulation of the ubiquitin ligase activity of TRAF6, results in K63-linked polyubiquitylation of substrate proteins like NEMO and TRAF6 itself. K63-ubiquitylated TRAF6 binds to the NZF reader domain in TAB2/TAB3, which then recruits and activates TAK1, which, in turn, phosphorylates and activates IKK (Chen 2005).

In addition, an eighth chain type exists, linear ubiquitin chains, in which peptide bonds are formed between the amino-terminal methionine of a ubiquitin monomer and the carboxy-terminal carboxy group of another ubiquitin monomer. Linear ubiquitin chains are important for generating protein-binding surfaces and promote the activation of inflammation and stress-signaling pathways, such as those downstream from the tumor necrosis factor (TNF) receptor (Walczak et al. 2012). Furthermore, proteins can also be modified by the attachment of ubiquitin-like proteins, such as SUMO (for small ubiquitin-like molecule) and Nedd8 (for neural precursor cell expressed de- 
A

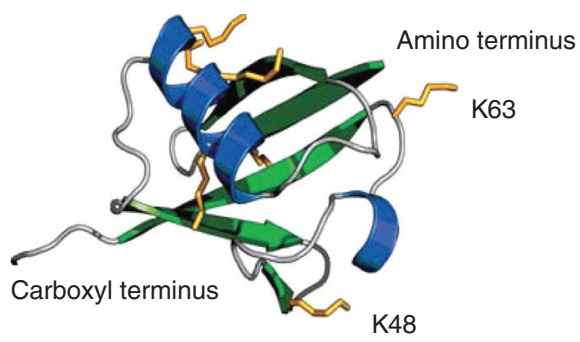

B
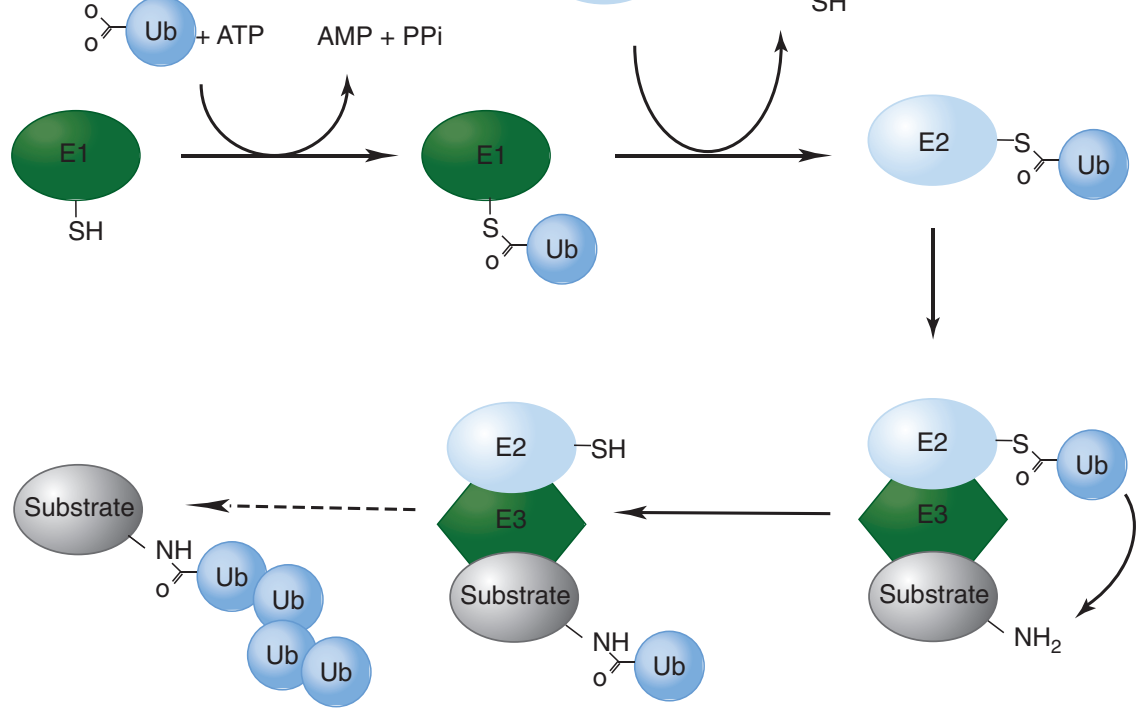

C

\begin{tabular}{|c|c|c|}
\hline Chain type & Form & Functions \\
\hline Monoubiquitylation & & $\begin{array}{l}\text { Protein localization } \\
\text { Endocytosis } \\
\text { Transcriptional regulation }\end{array}$ \\
\hline K48-linked chains & & Proteasomal degradation \\
\hline K63-linked chains & & $\begin{array}{l}\text { DNA repair } \\
\text { Protein localization } \\
\text { Protein activation }\end{array}$ \\
\hline $\begin{array}{l}\text { Other homotypic chains } \\
\text { (K6, K11, K27, K29, K33) }\end{array}$ & & $\begin{array}{l}\text { Proteasomal degradation } \\
\text { Protein activation } \\
\text { ER-associated degradation }\end{array}$ \\
\hline Linear chains (M1) & & $\begin{array}{l}\mathrm{NF}-\kappa \mathrm{B} \text { signaling } \\
\text { (understudied in general) }\end{array}$ \\
\hline Mixed chains & & Understudied in general \\
\hline Branched chains & & Understudied in general \\
\hline
\end{tabular}

Figure 7. Protein ubiquitylation. (A) Structure of the ubiquitin monomer, highlighting the amino and carboxyl termini, as well as key lysine residues. (B) Schematic depiction of the posttranslational modification of substrate proteins with ubiquitin. Ubiquitin is added to proteins through a three-step enzymatic reaction featuring a ubiquitin-activating enzyme (E1), a ubiquin-conjugating enzyme (E2), and a ubiquitin ligase (E3). Subsequent rounds of ubiquitylation can result in the formation of ubiquitin chains. $(C)$ Ubiquitin chain diversity. Ubiquitin contains seven lysine residues, each of which can be used as the anchorage point for subsequent ubiquitin monomers, in homotypic (same linkage throughout chain), heterotypic (mixed chains), or branched fashion (multiple ubiquitin monomers conjugated to a single ubiquitin). In addition, the amino-terminal methionine on a ubiquitin monomer linked to a substrate protein can be linked to the carboxy-terminal end of another ubiquin monomer (linear chains). Although all of these forms have been shown to exist in cells, physiological roles for many of these chains are still being elucidated. 
velopmentally down-regulated 8). Like K63 and linear ubiquitin chains, these molecules are thought to control protein-protein interactions rather than regulate protein degradation.

\section{CONCLUDING REMARKS: WHAT DOES THE FUTURE HOLD?}

Modulation of proteins represents the frontline response of most signaling systems. Many proteins are exquisitely sensitive to even very small posttranslational chemical modifications, such as phosphorylation, methylation, and the other posttranslational modifications highlighted here. These modifications can create new protein-protein binding surfaces or alter the conformation or localization of the target protein (which can, in turn, offer new protein-protein interaction possibilities). Furthermore, these modifications can dramatically alter the abundance of a protein in both positive (as in the case of signaling driving transcription) and negative directions (as in the case of ubiquitinmediated degradation).

An equally important question regarding posttranslational changes that modulate signal transduction is not "what" or "how," but rather "why." Why have these signaling systems used so much regulation at the protein level? Why are these complex regulatory mechanisms preferred? Many benefits have been proposed (and some validated) for the types of regulatory complexity that are seen in signaling biology, including signaling speed, robustness, reversibility, accuracy, and/or sensitivity that may be required for certain biological responses. The greatest benefit of these designs, however, is their diversity. Signaling processes were selected not to maximize efficiency but rather to maximize possibility. The modular organization of signaling components allows them to be imported into new biological contexts, where they may create new biological functions. This may be best illustrated by the roles of protein ubiquitylation in inactivating signals in some biological contexts and activating signals in others. Thus, using the tool kit of protein modules that function as readers, writers, and/or erasers, along with changes in protein abundance and location, signaling systems have evolved the potential to use a very limited list of parts to respond to a nearly limitless set of cues.

Although our knowledge of protein regulation in signal transduction is broad, it is important to stress that it is only deep at the detailed molecular level in a limited number of areas. Much remains to be learned, particularly with respect to how protein regulatory mechanisms work together at the systems level, and how protein regulatory behavior can be captured in the language of mathematics (Azeloglu and Iyengar 2014). In addition, we can be sure that additional types of posttranslational modifications, new modular binding domains, and new mechanisms of protein regulation will emerge.

\section{REFERENCES}

* Reference is also in this collection.

Alexander J, Lim D, Joughin BA, Hegemann B, Hutchins JRA, Ehrenberger T, Ivins F, Sessa F, Hudecz O, Nigg EA, et al. 2011. Spatial exclusivity combined with positive and negative selection of phosphorylation motifs is the basis for context-dependent mitotic signaling. SciSignal 4: ra42.

Ambros V. 2001. microRNAs: Tiny regulators with great potential. Cell 107: $823-826$.

Ambros V. 2011. MicroRNAs and developmental timing. Curr Opin Genet Dev 21: 511-517.

* Azeloglu EU, Iyengar R. 2014. Signaling networks: Information flow, computation, and decision making. Cold Spring Harb Perspect Med doi: $10.1101 /$ cshperspect.a005934.

Bieging KT, Attardi LD. 2012. Deconstructing p53 transcriptional networks in tumor suppression. Trends Cell Biol 22: 97-106.

Bivona TG, Pérez De Castro I, Ahearn IM, Grana TM, Chiu VK, Lockyer PJ, Cullen PJ, Pellicer A, Cox AD, Philips MR. 2003. Phospholipase Cy activates Ras on the Golgi apparatus by means of RasGRP1. Nature 424: 694-698.

Bos JL, Rehmann H, Wittinghofer A. 2007. GEFs and GAPs: Critical elements in the control of small G proteins. Cell 129: 865-877.

Boutin JA. 1997. Myristoylation. Cell Signal 9: 15-35.

Brown CJ, Lain S, Verma CS, Fersht AR, Lane DP. 2009. Awakening guardian angels: Drugging the p53 pathway. Nat Rev Cancer 29: 862-873.

Burnett G, Kennedy EP. 1954. The enzymatic phosphorylation of proteins. J Biol Chem 211: 969-980.

* Cantrell D. 2014. Signaling in lymphocyte activation. Cold Spring Harb Perspect Biol doi: 10.1101/cshperspect.a018788.

Casey PJ. 1995. Protein lipidation in cell signaling. Science 268: 221-225.

Chen ZJ. 2005. Ubiquitin signalling in the NF-кB pathway. Nat Cell Biol 7: $758-765$.

Chuderland D, Konson A, Seger R. 2008. Identification and characterization of a general nuclear translocation signal in signaling proteins. Mol Cell 31: 850-861.

Chung KY, Rasmussen SGF, Liu T, Li S, Devree BT, Chae PS, Calinski D, Kobilka BK, Woods VL, Sunahara RK. 2011. Conformational changes in the $G$ protein Gs induced by the $\beta 2$ adrenergic receptor. Nature 477: 611-615.

Ciechanover A. 2012. Intracellular protein degradation: From a vague idea thru the lysosome and the ubiquitin-proteasome system and onto human diseases and drug targeting. Biochim Biophys Acta 1824: 3-13.

Dias WB, Cheung WD, Hart GW. 2012. O-GlcNAcylation of kinases. Biochem Biophys Res Commun 422: 224-228.

Di Guglielmo GM, Baass PC, Ou WJ, Posner BI, Bergeron JJ. 1994. Compartmentalization of SHC, GRB2 and mSOS, and hyperphosphorylation of Raf-1 by EGF but not insulin in liver parenchyma. EMBO J 13: 4269-4277.

Dohlman HG, Jones JC. 2012. Signal activation and inactivation by the $\mathrm{G} \alpha$ helical domain: A long-neglected partner in $\mathrm{G}$ protein signaling. Sci Signal 5: re2-re2.

* Duronio RJ, Xiong Y. 2013. Signaling pathways that control cell proliferation. Cold Spring Harb Perspect Biol 5: a008904.

Elion EA. 2001. The Ste5p scaffold. J Cell Sci 114: 3967-3978.

Engström W, Ward A, Moorwood K. 2010. The role of scaffold proteins in JNK signalling. Cell Prolif 43: 56-66.

Filippakopoulos P, Picaud S, Mangos M, Keates T, Lambert J-P, BarsyteLovejoy D, Felletar I, Volkmer R, Müller S, Pawson T, et al. 2012. 
Histone recognition and large-scale structural analysis of the human bromodomain family. Cell 149: 214-231.

Foster MW, Hess DT, Stamler JS. 2009. Protein S-nitrosylation in health and disease: A current perspective. Trends Mol Med 15: 391-404.

Gingras AC, Gygi SP, Raught B, Polakiewicz RD, Abraham RT, Hoekstra MF, Aebersold R, Sonenberg N. 1999. Regulation of 4E-BP1 phosphorylation: A novel two-step mechanism. Genes Dev 13: 1422-1437.

Hara K, Yonezawa K, Kozlowski MT, Sugimoto T, Andrabi K, Weng QP, Kasuga M, Nishimoto I, Avruch J. 1997. Regulation of eIF-4E BP1 phosphorylation by mTOR. J Biol Chem 272: 26457-26463.

* Heldin C-H, Lu B, Evans R, Gutkind JS. 2014. Signals and receptors. Cold Spring Harb Perspect Biol doi: 10.1101/cshperspect.a005900.

Hepler JR, Gilman AG. 1992. G proteins. Trends Biochem Sci 17: 383387.

Hershko A, Ciechanover A. 1998. The ubiquitin system. Annu Rev Biochem 67: 425-479.

Hung MC, Link W. 2011. Protein localization in disease and therapy. J Cell Sci 124: 3381-3392.

Ikeda F, Dikic I. 2008. Atypical ubiquitin chains: New molecular signals. EMBO Rep 9: 536-542.

Jin J, Pawson T. 2012. Modular evolution of phosphorylation-based signalling systems. Philos Trans R Soc B Biol Sci 367: 2540-2555.

Kirkin V, Dikic I. 2007. Role of ubiquitin- and Ubl-binding proteins in cell signaling. Curr Opin Cell Biol 19: 199-205.

Kötting C, Kallenbach A, Suveyzdis Y, Wittinghofer A, Gerwert K. 2008. The GAP arginine finger movement into the catalytic site of Ras increases the activation entropy. Proc Natl Acad Sci 105: 6260-6265.

Krebs EG, Fischer EH. 1956. The phosphorylase b to a converting enzyme of rabbit skeletal muscle. Biochim Biophys Acta 20: 150-157.

Laplante M, Sabatini DM. 2012. mTOR signaling in growth control and disease. Cell 149: 274-293.

Lefkowitz RJ, Shenoy SK. 2005. Transduction of receptor signals by $\beta$-arrestins. Science 308: 512-517.

Letunic I, Doerks T, Bork P. 2011. SMART 7: Recent updates to the protein domain annotation resource. Nucleic Acids Res 40: D302-D305.

Levene PA, Alsberg CL. 1906. The cleavage products of vitellin. J Biol Chem 2: 127-133.

* Lim KH, Staudt LM. 2013. Toll-like receptor signaling. Cold Spring Harb Perspect Biol 5: a011247.

Lima B, Forrester MT, Hess DT, Stamler JS. 2010. S-Nitrosylation in cardiovascular signaling. Circ Res 106: 633-646.

Lipmann FA, Levene PA. 1932. Serinephosphoric acid obtained on hydrolysis of vitellinic acid. J Biol Chem 98: 109-114.

Lowery DM, Lim D, Yaffe MB. 2005. Structure and function of Polo-like kinases. Oncogene 24: 248-259.

Lynch KW. 2007. Regulation of alternative splicing by signal transduction pathways. Adv Exp Med Biol 623: 161-174.

Macdonald N, Welburn JPI, Noble MEM, Nguyen A, Yaffe MB, Clynes D, Moggs JG, Orphanides G, Thomson S, Edmunds JW, et al. 2005. Molecular basis for the recognition of phosphorylated and phosphoacetylated histone H3 by 14-3-3. Mol Cell 20: $199-211$.

Malumbres M, Barbacid M. 2005. Mammalian cyclin-dependent kinases. Trends Biochem Sci 30: 630-641.

Maurer-Stroh S, Dickens NJ, Hughes-Davies L, Kouzarides T, Eisenhaber F, Ponting CP. 2003. The Tudor domain "Royal Family": Tudor, plant Agenet, Chromo, PWWP and MBT domains. Trends Biochem Sci 28: 69-74.

Maxfield FR. 2002. Plasma membrane microdomains. Curr Opin Cell Biol 14: 483-487.

McLaughlin S, Aderem A. 1995. The myristoyl-electrostatic switch: A modulator of reversible protein-membrane interactions. Trends Biochem Sci 20: 272-276.

Momand J, Zambetti GP, Olson DC, George D, Levine AJ. 1992. The $m d m-2$ oncogene product forms a complex with the p53 protein and inhibits p53-mediated transactivation. Cell 69: 1237-1245.
* Morrison DK. 2012. MAPK kinase pathways. Cold Spring Harb Perspect Biol 4: a011254.

Muratani M, Tansey WP. 2003. How the ubiquitin-proteasome system controls transcription. Nat Rev Mol Cell Biol 4: 192-201.

Murphy JE, Padilla BE, Hasdemir B, Cottrell GS, Bunnett NW. 2009. Endosomes: A legitimate platform for the signaling train. Proc Natl Acad Sci 106: 17615-17622.

Nadolski MJ, Linder ME. 2007. Protein lipidation. FEBS J 274: 5202-5210.

* Newton AC, Bootman M, Scott JD. 2014. Second messengers. Cold Spring Harb Perspect Biol doi: 10.1101/cshperspect.a005926.

Obenauer JC, Yaffe MB. 2004. Computational prediction of proteinprotein interactions. Methods Mol Biol 261: 445-468.

Obenauer JC, Cantley LC, Yaffe MB. 2003. Scansite 2.0: Proteome-wide prediction of cell signaling interactions using short sequence motifs. Nucleic Acids Res 31: 3635-3641.

Pei H, Zhang L, Luo K, Qin Y, Chesi M, Fei F, Bergsagel PL, Wang L, You Z, Lou Z. 2011. MMSET regulates histone H4K20 methylation and 53BP1 accumulation at DNA damage sites. Nature 469: 124-128.

Perdiz D, Mackeh R, Poüs C, Baillet A. 2011. The ins and outs of tubulin acetylation: More than just a post-translational modification? Cell Signal 23: 763-771.

Privé GG, Milburn MV, Tong L, de Vos AM, Yamaizumi Z, Nishimura S, Kim SH. 1992. X-Ray crystal structures of transforming p21 ras mutants suggest a transition-state stabilization mechanism for GTP hydrolysis. Proc Natl Acad Sci 89: 3649-3653.

Pullen N, Thomas G. 1997. The modular phosphorylation and activation of p70s6k. FEBS Lett 410: 78-82.

Radi R. 2013. Protein tyrosine nitration: Biochemical mechanisms and structural basis of functional effects. Acc Chem Res 46: 550-559.

Rasmussen SGF, Devree BT, Zou Y, Kruse AC, Chung KY, Kobilka TS, Thian FS, Chae PS, Pardon E, Calinski D, et al. 2011. Crystal structure of the $\beta 2$ adrenergic receptor-Gs protein complex. Nature 477: 549-555.

Resh MD. 2012. Targeting protein lipidation in disease. Trends Mol Med 18: $206-214$.

* Rhind N, Russell P. 2012. Signaling pathways that regulate cell division. Cold Spring Harb Perspect Biol 4: a005942.

Roy S, Plowman S, Rotblat B, Prior IA, Muncke C, Grainger S, Parton RG, Henis YI, Kloog Y, Hancock JF. 2005. Individual palmitoyl residues serve distinct roles in $\mathrm{H}$-ras trafficking, microlocalization, and signaling. Mol Cell Biol 25: 6722-6733.

* Sever R, Brugge JS. 2014. Signaling in cancer. Cold Spring Harb Perspect Med doi: 10.1101/cshperspect.a006098.

* Sever R, Glass CK. 2013. Signaling by nuclear receptors. Cold Spring Harb Perspect Biol 5: a016709.

Siderovski DP, Willard FS. 2005. The GAPs, GEFs, and GDIs of heterotrimeric G-protein $\alpha$ subunits. Int J Biol Sci 1: 51.

Slessareva JE, Routt SM, Temple B, Bankaitis VA, Dohlman HG. 2006. Activation of the phosphatidylinositol 3-kinase Vps34 by a G protein $\alpha$ subunit at the endosome. Cell 126: 191-203.

Sprang SR. 1997. G protein mechanisms: Insights from structural analysis. Annu Rev Biochem 66: 639-678.

Sudakin V, Ganoth D, Dahan A, Heller H, Hershko J, Luca FC, Ruderman JV, Hershko A. 1995. The cyclosome, a large complex containing cyclin-selective ubiquitin ligase activity, targets cyclins for destruction at the end of mitosis. Mol Biol Cell 6: 185-197.

Temple BRS, Jones AM. 2007. The plant heterotrimeric G-protein complex. Annu Rev Plant Biol 58: 249-266.

Tesmer JJ, Berman DM, Gilman AG, Sprang SR. 1997. Structure of RGS4 bound to $\mathrm{AlF}_{4^{-}}$-activated $\mathrm{G}_{\mathrm{i}} \mathrm{\alpha}_{1}$ : Stabilization of the transition state for GTP hydrolysis. Cell 89: 251-261.

Walczak H, Iwai K, Dikic I. 2012. Generation and physiological roles of linear ubiquitin chains. BMC Biol 10: 23.

Wang Q, Zhang Y, Yang C, Xiong H, Lin Y, Yao J, Li H, Xie L, Zhao W, Yao $\mathrm{Y}$, et al. 2010. Acetylation of metabolic enzymes coordinates carbon source utilization and metabolic flux. Science 327: 1004-1007. 
Weis WI, Kobilka BK. 2008. Structural insights into G-protein-coupled receptor activation. Curr Opin Struct Biol 18: 734-740.

Wennerberg K. 2005. The Ras superfamily at a glance. J Cell Sci 118: 843846.

Wise A, Gearing K, Rees S. 2002. Target validation of G-protein coupled receptors. Drug Discov Today 7: 235-246.

Wu X, Brewer G. 2012. The regulation of mRNA stability in mammalian cells: 2.0. Gene 500: 10-21.
Xu W, Doshi A, Lei M, Eck MJ, Harrison SC. 1999. Crystal structures of cSrc reveal features of its autoinhibitory mechanism. Mol Cell 3: 629638.

Yaffe MB, Smerdon SJ. 2004. The use of in vitro peptide library screens in the analysis of phosphoserine/threonine-binding domain structure and function. Annu Rev Biophys Biomol Struct 33: 225-244.

Zastrow von M, Sorkin A. 2007. Signaling on the endocytic pathway. Curr Opin Cell Biol 19: 436-445. 


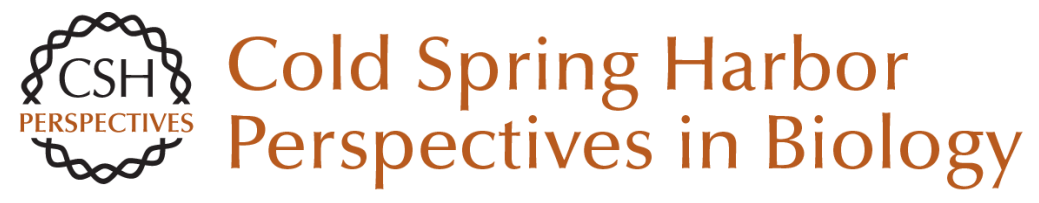

\section{Protein Regulation in Signal Transduction}

Michael J. Lee and Michael B. Yaffe

Cold Spring Harb Perspect Biol 2016; doi: 10.1101/cshperspect.a005918

Subject Collection Signal Transduction

Cell Signaling and Stress Responses Gökhan S. Hotamisligil and Roger J. Davis

Protein Regulation in Signal Transduction Michael J. Lee and Michael B. Yaffe

Synaptic Signaling in Learning and Memory Mary B. Kennedy

Vertebrate Reproduction Sally Kornbluth and Rafael Fissore

Signaling in Lymphocyte Activation Doreen Cantrell

Signaling in Muscle Contraction Ivana Y. Kuo and Barbara E. Ehrlich

Toll-Like Receptor Signaling Kian-Huat Lim and Louis M. Staudt

Signaling Pathways that Regulate Cell Division Nicholas Rhind and Paul Russell
Second Messengers

Alexandra C. Newton, Martin D. Bootman and John D. Scott

Signals and Receptors Carl-Henrik Heldin, Benson Lu, Ron Evans, et al.

Cell Death Signaling Douglas R. Green and Fabien Llambi

Signaling Networks that Regulate Cell Migration Peter Devreotes and Alan Rick Horwitz

Signaling Networks: Information Flow, Computation, and Decision Making Evren U. Azeloglu and Ravi lyengar

Signal Transduction: From the Atomic Age to the Post-Genomic Era Jeremy Thorner, Tony Hunter, Lewis C. Cantley, et al.

Signaling by the TGF $\beta$ Superfamily Jeffrey L. Wrana

Subversion of Cell Signaling by Pathogens Neal M. Alto and Kim Orth

For additional articles in this collection, see http://cshperspectives.cshlp.org/cgi/collection/

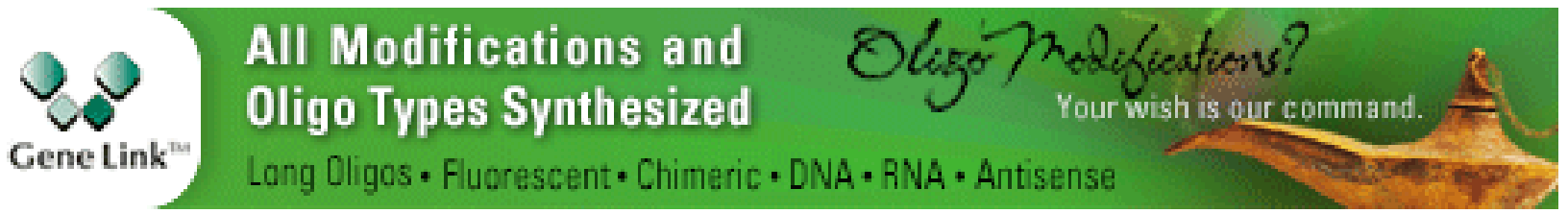

Copyright @ 2016 Cold Spring Harbor Laboratory Press; all rights reserved 